\title{
INCLUSÃO DE SURDO: REFLEXÃO DAS PRÁTICAS PEDAGÓGICAS DOS PROFESSORES NO ENSINO DE LIBRAS A UM ALUNO SURDO NA EMEF CORONEL RAIMUNDO LEÃO CAMETÁ/PA
}

\author{
Doralice farias Virgolino ${ }^{1}$ \\ José Miguel Pereira Borges ${ }^{2}$ \\ Marli do Socorro Mota ferreira ${ }^{3}$
}

\section{Resumo:}

O presente trabalho trata da inclusão de surdo. Para tanto, faz uma reflexão das práticas pedagógicas dos professores no ensino de LIBRAS a um aluno surdo na EMEF Coronel Raimundo Leão, para realização deste, opinamos por uma pesquisa de campo, pois objetiva realizar a aproximação entre o pesquisador e o objeto da pesquisa no campo de atuação, seguindo uma abordagem qualitativa, por entender que o pesquisador procura compreender com mais detalhes os fenômenos estudados, em sua profundidade as ações do sujeito, para a análise das investigações, utilizamos o método de Bardin, conhecido como análise de conteúdo, que serviu para analisar como os professores desenvolvem suas práticas pedagógicas no âmbito da inclusão dos surdos. Por saber que a inclusão está garantido em Lei, o processo inclusivo não é fácil, os professores precisam de formação continuada para aprimorar cada vez mais suas práticas pedagógicas. Apesar da inclusão que vem sendo discutida intensamente nas últimas décadas, ainda há muitas lacunas que precisam ser compreendidas pela comunidade escolar e sociedade, para que de fato, todos tenham a plena consciência do processo inclusivo e valorização às diferenças de cada um.

Palavras Chave: Inclusão. Ensino de Libras. Alunos Surdos.

${ }^{1}$ Graduada em Pedagogia pela Universidade do Vale do Acaraú (UVA). Pós Graduada em Educação Especial e Educação Inclusiva pela Faculdade Internacional de Curitiba (FACINTER), Pós Graduada em Ensino de Libras, pela Faculdade de Ciências Wenceslau Braz (FACIBRA), da Matemática pela Faculdade de Patrocínio. Pós Graduado em Língua Brasileira de Sinais (LIBRAS), Pós graduada em Psicopedagogia com ênfase em Educação Inclusiva, pela Faculdade de Patrocínio (FAP). Mestranda em Ciências da Educação pela Facultad Interamericana de Ciências Sociales. E-mail: doralicevirgolino10@ gmail.com

${ }^{2}$ Graduado em Pedagogia pela Universidade do Vale do Acaraú (UVA). Graduado em Matemática pela Universidade Federal do Pará (UFPA). Pós Graduado em Gestão do Trabalho Pedagógico: Orientação e Supervisão Escolar pelo Centro Universitário Internacional (UNINTER). Pós Graduado em Metodologia da Matemática pela Faculdade de Patrocínio. Pós Graduado em Língua Brasileira de Sinais (LIBRAS) pelo Centro Universitário Leonardo da Vinci (UNIASSELVI). Pós Graduando em Educação Especial Inclusiva pelo Centro Universitário Leonardo da Vinci (UNIASSELVI). Mestrando em Ciências da Educação pela Facultad Interamericana de Ciências Sociales. E-mail: borges.miguel_@hotmail.com

${ }^{3}$ Graduada em Letras - Língua Portuguesa pela Universidade Federal do Pará (UFPA), Graduada em Pedagogia pela Universidade Vasconcelos e Souza (Centro Educacional Eliã). Pós Graduada em Língua Portuguesa: Uma Abordagem Textual pela Universidade Federal do Pará (UFPA). Pós Graduada em Coordenação Pedagógica pela Faculdade do Noroeste de Minas (FINOM). Pós Graduada em LIBRAS: Docência e Interpretação pela Faculdades Integradas do 
Tapajós (FIT). Pós Graduada em Psicopedagogia com Ênfase em Educação Inclusiva pela Faculdade de Patrocínio (FAP). Graduanda em Língua Brasileira de Sinais - LIBRAS pelo Centro Universitário Leonardo da Vinci (UNIASSELVI). Mestranda em Ciência da Educação pela Facultad Interamericana de Ciências Sociales. E-mail: marlimota25@gmail.com

\section{INTRODUÇÃO}

Este trabalho trata da inclusão de surdo, onde faz uma reflexão das práticas pedagógicas dos professores acerca do ensino da Língua Brasileira de Sinais (LIBRAS) a um aluno surdo da EMEF Coronel Raimundo Leão Cametá/Pará. Embora o Ensino de Libras esteja garantido na Lei, este tema tem sido alvo de preocupação dos profissionais da escola, sobretudo, ao receber alunos com surdez.

Evidencia-se a preocupação dos professores, devido à falta de qualificação desses profissionais. Haja vista, sentirem-se angustiados ao trabalhar o Ensino da Libras com os alunos. Diante das dificuldades apresentadas pelos docentes em garantir o ensino da LIBRAS ao aluno surdo, traçamos como objetivo, refletir como se dá as práticas pedagógicas dos professores no ensino de Libras ao aluno surdo. Contudo, questiona-se quais os desafios da escola para garantir a inclusão do aluno surdo?

A inclusão dos surdos perpassa por grandes desafios, pois não basta apenas garantir ambientes educacionais adequados, é preciso garantir ao aluno, acompanhamento de profissionais qualificados na área para atender, envolver e promover oportunidades de comunicação e socialização para o aluno incluso. Segundo Mendes,

[...] inclusão estabelece que as diferenças humanas são normais, mas ao mesmo tempo reconhece que a escola atual tem provocado ou acentuado desigualdades associadas à existência de diferenças de origem pessoal, social, cultural e política, e é nesse sentido que ela prega a necessidade de reestruturação do sistema educacional para prover uma educação de qualidade a todas as crianças (2002, p.64).

No processo inclusivo não deve existir diferenças entre os alunos, porém ainda existem disparidades entre os discentes nas escolas. Mendes adverte sobre as reestruturações das escolas, que devem acontecer de imediato nos diversos segmentos do sistema educacional, pois anseia que a educação seja proporcionada para todos os alunos independentemente de diferenças raciais ou classes sociais.

A partir das dificuldades apresentadas acerca da inclusão dos surdos na EMEF Coronel Raimundo Leão, despertou o interesse em realizar um estudo com o enfoque nas Práticas 
Pedagógicas dos Professores quanto ao ensino da LIBRAS ao aluno surdo, com a proposta de entender as estratégias que a escola utiliza para garantir a inclusão desses alunos. O trabalho portanto, foi organizado em três capítulos:

O Capítulo 1, intitulado, "Percurso das Legislações que Contribuíram para a Inclusão no Brasil a Partir da Década de 1990”, faz uma incursão do percurso das legislações que contribuíram para o fortalecimento do processo de inclusão no Brasil.

O capítulo 2, intitulado "O Ensino da Libras no Processo de Inclusão de Surdos", trata dos desafios que os profissionais da educação enfrentam no cotidiano para trabalhar a Libras com alunos surdos incluídos na EMEF Coronel Raimundo Leão Cametá/Pa.

O capítulo 3, tem como título "Resultados Obtidos a Partir das Reflexões das Práticas Pedagógicas dos Professores com um Aluno Surdo no Contexto da Inclusão", aborda sobre os resultados obtidos a partir das reflexões das práticas pedagógicas dos professores da EMEF Coronel Raimundo Leão no contexto da inclusão do aluno com deficiência auditiva.

\section{PERCURSO DAS LEGISLAÇÕES QUE CONTRIbUÍRAM PARA A INCLUSÃO NO BRASIL A PARTIR DA DÉCADA DE 1990}

Este capítulo faz uma percurso das legislações que contribuíram para o processo de inclusão no Brasil. A partir da década de 1990, época em que as reformas na área inclusiva começam a ser discutidas com mais veemência. Nesse período, as discussões ganham forças em detrimento dos encontros internacionais e nacionais que vinham sendo debatidos sobre o contexto inclusivo para traçar diretrizes acerca da inclusão em Jomtien/Tailândia, em 1990, onde foi elaborado a "Declaração Mundial de Educação para Todos" (BRASIL, 1990). Ficando estabelecido a educação como um direito fundamental de todos.

Em 1994, foi elaborado a "Declaração de Salamanca" (BRASIL, 1994), na Conferência Mundial sobre Educação Especial, em Salamanca na Espanha, teve como objetivo fornecer diretrizes para as reformas educacionais nos movimentos inclusivo, garantindo o acesso à educação às pessoas com algum tipo de deficiência, independentemente de raças ou classes sociais que pertencem. Perpassa pela necessidade de mudanças nos sistemas educacionais e de reestruturação das escolas de modo a garantir a inclusão.

Essas conferências realizadas durante a década de 1990, para discussões e elaborações das diretrizes foram fundamentais para alavancar as reformas inclusivas no Brasil. Portanto, foi a partir dessa década, que o processo de inclusão passou a ganhar expressividade pelos diversos órgãos educacionais, exigindo dos professores comprometimento para lidar com as reformas inclusivas. 
Motivadas pelos encontros realizados em Jomtien/Tailândia, em 1990, culminando com a "Declaração Mundial de Educação para Todos" (BRASIL, 1990), como também a Conferência Mundial de Educação Especial, realizado em Salamanca/Espanha em 1994, fundamentada na "Declaração de Salamanca" (BRASIL, 1994). Esses documentos, garantiu o acesso à educação para todas as pessoas que tenham algum tipo de deficiência.

Motivados pelos encontros realizados para discussões e implementações das diretrizes da educação especial inclusiva, em 1996, houve a promulgação da Lei de Diretrizes e Bases da Educação, Lei 9394/96, onde preconiza nos artigos 58 e 59:

[...] Entende-se por educação especial, para os efeitos desta Lei, a modalidade de educação escolar oferecida preferencialmente na rede regular de ensino, para educandos com deficiência. Os sistemas de ensino assegurarão aos educandos com deficiência, transtornos globais do desenvolvimento e altas habilidades ou superdotação; assegurarão currículos, métodos, técnicas, recursos educativos e organização específicos, para atender às suas necessidades, visando a sua efetiva integração na vida em sociedade, inclusive condições adequadas para os que não revelarem capacidade de inserção no trabalho competitivo, mediante articulação com os órgãos oficiais afins, bem como para aqueles que apresentam uma habilidade superior nas áreas artística, intelectual ou psicomotora, garante professores com especialização adequada em nível médio ou superior, para atendimento especializado, bem como professores do ensino regular capacitados para a integração desses educandos nas classes comuns (LDB, 2018, p.39,40).

A LDB, assegura no capítulo $\mathrm{V}$, precisamente nos artigos 58 e 59, que os sistemas de ensino deverão garantir aos alunos com algum tipo de deficiência, estabelecimentos de ensino que sejam adequados para atender as necessidades dos educandos. Dessa forma, as escolas deverão se adequar para garantir um ambiente inclusivo, juntamente com os professores que precisam se capacitar com formações específicas para trabalhar o processo inclusivo dos discentes e assim, garantir a universalização do ensino.

Em 1999, foi publicada as Diretrizes da Política Nacional para a Integração da Pessoa Portadora de Deficiência, através do Decreto 3298/99 (1999), que regulamentou a Lei no 7.853 , de 24 de outubro de 1989, a qual dispõe sobre a Política Nacional para a Integração da Pessoa Portadora de Deficiência, onde define "a educação especial como uma modalidade transversal a todos os níveis e modalidades de ensino, enfatizando a atuação complementar da educação especial ao ensino regular”. Consolida as normas de proteção, e dá outras providências.

No capítulo I, nos artigos $1^{\circ}$ e $2^{\circ}$, asseguram que, 
A Política Nacional para a Integração da Pessoa Portadora de Deficiência compreende o conjunto de orientações normativas que objetivam assegurar o pleno exercício dos direitos individuais e sociais das pessoas portadoras de deficiência. Cabe aos órgãos e às entidades do Poder Público assegurar à pessoa portadora de deficiência o pleno exercício de seus direitos básicos, inclusive dos direitos à educação, à saúde, ao trabalho, ao desporto, ao turismo, ao lazer, à previdência social, à assistência social, ao transporte, à edificação pública, à habitação, à cultura, ao amparo à infância e à maternidade, e de outros que, decorrentes da Constituição e das leis, propiciem seu bem-estar pessoal, social e econômico (Decreto, 3.298/1999).

De acordo ainda com o Decreto 3298/99 que normatiza a Política Nacional para a Integração da Pessoa Portadora de deficiência, ficam estabelecidos: a oferta, obrigatória e gratuita, da Educação Especial em estabelecimentos públicos de ensino; o acesso de alunos portadores de deficiência aos benefícios conferidos aos demais educandos, inclusive material escolar, merenda escolar e bolsas de estudo; a matrícula compulsória em cursos regulares de estabelecimentos públicos e particulares de pessoas portadoras de deficiência capazes de se integrarem no sistema regular de ensino, entres outros direitos como: saúde, trabalho, lazer.

Delineando assim, os direitos gratuitos de todas as pessoas com deficiência em estabelecimentos públicos de ensino, tanto da matrícula, quanto dos materiais escolares, entre outros benefícios. É importante frisar que, além dos direitos garantidos dos recursos necessários, faz-se necessário garantir estruturas adequadas ao aluno para que ele possa se sentir amparado e fazer valer dos seus direitos básicos garantidos por lei.

Outro marco importante que contribuiu nesse processo de transição da Educação Especial, foi Convenção Interamericana para a Eliminação de Todas as Formas de Discriminação contra as Pessoas Portadoras de Deficiência, conhecida como Convenção de Guatemala, aprovado pelo Conselho Permanente na sessão realizada em 26 de maio de 1999, (promulgada pelo Decreto $\mathrm{n}^{\circ} 3.956 / 2001$ ). Nela reafirma os direitos fundamentais dos cidadãos e impede qualquer forma de discriminação contra pessoas deficientes e exclusão dos direitos humanos, ou seja, qualquer pessoa tem os mesmos direitos de buscar seus espaços inclusivos na sociedade.

Em 2001, foi promulgado a resolução do CNE/CEB $n^{\circ}$ 02/2001, estabelecendo as Diretrizes Nacionais para Educação Especial na Educação Básica, no sentido de construir as estruturas educacionais inclusivas para os alunos no atendimento de suas diversidades. Em seu art. $1^{\circ}$, retrata que, a presente Resolução institui as Diretrizes Nacionais para "a educação dos alunos que apresentam necessidades educacionais especiais, na Educação Básica, em todas as suas etapas e modalidades" (CNE, 2001). No art. $2^{\circ}$, determina que, 
Os sistemas de ensino devem matricular todos os alunos, cabendo às escolas organizarem-se para o atendimento aos educandos com Necessidades Educativas Especiais (NEE), assegurando condições necessárias para uma educação de qualidade para todos. (CNE, 2001).

Ainda em 2001, com a necessidade de ampliação das diretrizes da Educação Especial, garantindo o atendimento especializado em caráter complementar ou suplementar a escolarização do aluno. É proposto o Plano Nacional de Educação (PNE), através da Lei no 10.172/2001, estabelecendo objetivos e metas para a educação especial inclusiva, para atender as necessidades dos alunos, foi o grande avanço da época, pois era proposto, construções de escolas inclusivas para contemplar os alunos deficientes.

Neste sentido, o MEC ao elaborar as Diretrizes Nacionais de Educação Especial considera que a inclusão é:

A construção de uma sociedade inclusiva é um processo de fundamental importância para o desenvolvimento e a manutenção de um Estado democrático. Entende-se por inclusão a garantia, a todos, do acesso contínuo ao espaço comum da vida em sociedade, sociedade essa que deve estar orientada por ações de acolhimento a diversidades humana, de aceitação das diferenças individuais, de esforço coletivo na equiparação de oportunidades de desenvolvimento, com qualidade, em todas as dimensões da vida (CNE, 2001, p.13).

No artigo $2^{\circ}$, seguindo o viés de alteração nas Diretrizes Nacionais para a Educação Especial na Educação Básica, através da Resolução CNE/CEB n ${ }^{\circ} 2 / 2001$, no artigo $2^{\circ}$, determinam que:

Os sistemas de ensino devem matricular todos os estudantes, cabendo às escolas organizarem-se para o atendimento aos educandos com necessidades educacionais especiais, assegurando as condições necessárias para uma educação de qualidade para todos. (MEC/SEESP, 2001).

O Ministério da Educação elaborou as diretrizes pautada no fortalecimento de uma sociedade inclusiva, onde os direitos fundamentais das pessoas que apresentam alguma deficiência estejam amparados por Lei, garantido assim, um Estado Democrático de direitos, pois entende-se que a inclusão é um processo que garante os direitos a todos que necessitam de acompanhamento para superar as necessidades independentemente do tipo de deficiência que possui, com o respeito as diferenças e os limites de cada um. 
Cabe as escolas, a organização e garantia das estruturas para realizar matrículas e atendimentos a todos os alunos que necessitam desse apoio e condições necessárias para fazer valer os direitos garantidos nas leis.

A educação inclusiva é um grande desafio a ser encarado pela sociedade e estabelecimentos de ensino, pois não basta apenas incluir os alunos com deficiência ou que apresente algum tipo de necessidades educacionais especiais, mas é preciso criar condições de aprendizagem aos alunos e fazer valer dos direitos garantidos por lei, um ambiente acolhedor para que possam desenvolver suas habilidades, além de sentir amparado pelo processo inclusivo, dando a garantia do direito à diversidade respeitando as diferenças e limitações de cada um.

Em 2003, o MEC lança o Programa "Educação Inclusiva: Direito a Diversidade" tendo como foco a formação dos professores e gestores, no sentido de colaborar com a mudança de sistema de ensino e inclusivos, visando: "Disseminar a política de educação inclusiva nos municípios brasileiros e apoiar a formação de gestores e educadores para efetivar a transformação dos sistemas educacionais em sistemas educacionais inclusivos" (BRASIL, 2006, p. 1).

A garantia do direito a diversidade gerou mudanças na proposta do ensino para a formação dos gestores e professores no sentido de garantir a política de educação inclusiva com pleno direito de acesso escolarização nas instituições de ensino dos diversos municípios brasileiros. Apesar das inversões nas mudanças do sistema de ensino para a propagação da efetivação da inclusão, evidencia-se as dificuldades na política da inclusão.

Atualmente a inclusão foi amparada pela Lei no 13.146/15 e está "destinada a assegurar e promover, em condições de igualdade o exercício dos direitos e das liberdades fundamentais por pessoa com deficiência, visando a inclusão social e cidadania".

As discussões foram intensas nessas três décadas, sobretudo no processo inclusivo. Contudo, os caminhos na política da inclusão foram traçados: os gestores Federais, Estaduais e Municipais, juntamente com a escola e sociedade, precisam abraçar a causa inclusiva para que os alunos possam estar amparados pelas Leis.

\section{O ENSINO DA LIBRAS NO PROCESSO DE INCLUSÃO DE SURDOS}

Este capítulo, trata do ensino de Libras no processo de inclusão de surdos. Fato este, que tem provocado grandes desafios aos profissionais da educação que precisam estar 
preparados para trabalhar a Língua de Sinais com alunos surdos nas escolas públicas do município de Cametá.

A língua brasileira de sinais (LIBRAS), é instrumento de fundamental importância para a interação e inclusão do sujeito surdo na sociedade, a mesma está amparada pela Lei no 10.436/02, de 24 de abril de 2002, Lei que reconhece a legitimidade da língua natural dos surdos, sendo regulamentada em 22 de Dezembro de 2005, através do decreto $\mathrm{n}^{\circ}$ 5.626/05, estabelecendo a inclusão da Libras como disciplina curricular no ensino público e privado como segunda língua oficial do Brasil, sua comunicação tem como foco principal a interação espontânea com as pessoas.

De acordo com GESSER,

A Libras é uma língua, não linguagem, pois ela tem todos os componentes pertinentes às línguas orais, como gramática, semântica, sintaxe e outros elementos, preenchendo, assim, os requisitos científicos para ser considerada instrumentalmente linguística com poder e força $(2009$, p. 225,226$)$.

Brito reforça ainda que,

As línguas de sinais são línguas naturais porque como as línguas orais surbgiram espontaneamente da interação entre pessoas e porque devido à sua estrutura permitem a expressão de qualquer conceito - descritivo, emotivo, racional, literal, metafórico, concreto, abstrato - enfim, permitem a expressão de qualquer significado decorrente da necessidade comunicativa e expressiva do ser humano (BRITO, 1998, p. 19).

O autor ressalta que, a Libras por ser uma língua natural do surdo, assim, como a língua oral, merece uma atenção especial das pessoas que precisam conhecer suas estruturas gramaticais de forma expressiva, se diferencia das demais, pois ser uma língua viso espacial, para poder se comunicar com os surdos através do uso das mãos, a Libras é uma língua de modalidade gestual-visual e que possui uma estrutura linguística semelhante a das diversas línguas de modalidade oral auditiva. Como todas as línguas orais auditivas possui uma gramática própria, definida pelos níveis linguísticos que são eles:

a) Fonológico (línguas orais auditivas) ou quirológico (línguas de sinais - arte de conversar por meio de sinais feitos com as mãos);

b) Morfológico - palavra/sinal ou item lexical;

c) Sintático - frase 
d) Semântico - significado

e) Pragmático - uso do significado - sentido

Por isso, faz-se necessário compreender a estrutura da língua. A LIBRAS é uma língua estruturada linguisticamente, como qualquer outro idioma. Neste sentido, é importante compreender que o processo de inclusão de alunos com surdez e o ensino de sua língua materna, tem se tornado um desafio para os professores que precisam ter o domínio desse idioma para trabalhar sua modalidade.

Neste sentido, a comunicação entre os sujeitos surdos e ouvintes, dar-se pelo uso da língua gestual, por isso, é imprescindível que o aluno surdo tenha o pleno domínio de sua língua materna, língua brasileira de sinais (LIBRAS) para poder se comunicar com outras pessoas. Fernandes retrata que,

A LIBRAS é uma língua de modalidade visual espacial que diferentemente das línguas orais auditivas, utilizam-se da visão para sua apropriação e de elementos corporais e faciais e organizados em movimentos no espaço para constituir unidades de sentido as palavras ou, como se referem os surdos, os sinais. Os sinais podem representar qualquer dado da realidade social, não se reduzindo a um simples sistema de gestos naturais, ou mímicas como pensa a maioria das pessoas. Aliás, esse é o principal mito em relação à língua de sinais, pois por utilizar as mãos e o corpo na comunicação, costuma-se compará-la à linguagem gestual, contextual e restrita a referentes concretos, palpáveis, transparentes que tem seu significado facilmente apreendido por que os observa $(2011, \mathrm{p} .82)$.

A Libras por ser uma língua visual espacial, requer muito empenho das pessoas para compreender os movimentos dos sinais nos espaços, pois não se trata de gestos ou mímicas e sim de sinais representados de acordo com os articuladores da língua de sinais. Por isso, é importante compreender os parâmetros que são utilizados no ensino de LIBRAS, para poder utilizar com os alunos no cotidiano da sala de aula, são eles: (OS CINCO PARÂMETROS DA LIBRAS).

1 - A configuração da mão: a configuração adotada pela mão, tem como resultado a posição dos dedos. Embora seja verdade que cada idioma tem seu próprio repertório de configurações, existem algumas que são as mais comuns porque são as mais simples;

2 - Ponto ou local de articulação: este parâmetro indica onde o sinal pode ser tocado no corpo ou no espaço sígnico, que é o espaço encontrado em frente do assinante. Ele é delimitado pela extensão máxima dos braços e ocorre acima da cabeça ou para frente. Deve-se dizer que no discurso normal as extremidades são articuladas em um espaço mais limitado que a extensão 
máxima que mencionamos e que, portanto, o tamanho do sinal pode ser comparado à intensidade da voz.

3 - Orientação/direcionalidade: é o plano em direção ao qual a palma da mão é orientada. Alguns sinais têm a mesma configuração, o mesmo ponto de articulação e o mesmo movimento, e diferem apenas na orientação da mão. É importante perceber como a modificação de um único parâmetro pode alterar completamente o significado do sinal.

4 - O movimento: os sinais geralmente não são estáticos em um local, mas, ao contrário, contêm algum movimento. Dessa forma, podemos entender que o parâmetro de movimento refere-se ao modo como as mãos se movimentam (movimento linear, em movimento da forma de sete arqueada, circular, simultânea ou alternada com ambas as mãos, etc.) e para onde estão movimentando (para a frente, em direção a direita, esquerda, etc.).

5 - Expressão facial e/ou corporal: também chamados de componentes não manuais: as expressões faciais e corporais, vocalizações parciais de palavras ou padrões labiais e movimentos dos olhos, cabeça e corpo. Eles têm um papel importante na produção de sinais, para que possam assumir que o sinal adquire um significado ou outro.

Enfatiza-se portanto, que os profissionais da educação que recebem alunos surdos nas suas salas de aulas, precisam conhecer os parâmetros que fundamentam a língua brasileira de sinais (LIBRAS), assim como, precisam saber que a língua possui uma estrutura linguística própria, que são elementos imprescindíveis para que o profissional tenha o conhecimento e domínio da LIBRAS.

Os professores precisam dominar a LIBRAS para poder garantir a comunicação e socialização com o sujeitos surdos. Dessa forma, ele pode tá contribuindo para o aprendizado e processo inclusivo dos educandos, pois de acordo com a Constituição Federal de 1988, em seu Art. 205: “A educação, direito de todos e dever do Estado e da família, será promovida e incentivada com a colaboração da sociedade, visando ao pleno desenvolvimento da pessoa, seu preparo para o exercício da cidadania" (C. F 1988).

Diante do contexto da inclusão dos alunos surdos, a escola juntamente com os profissionais, tem um papel fundamental nesse processo, que é garantir o ensino da LIBRAS a todos os educandos surdos e a permanência do aluno no estabelecimento de ensino, levando em consideração a sua peculiaridade e potencialidade na comunicação, tornando o ensino de LIBRAS aos discentes um instrumento prazeroso no sentido de garantir a inclusão dos alunos surdos. 


\section{RESULTADOS OBTIDOS A PARTIR DAS REFLEXÕES DAS PRÁTICAS PEDAGÓGICAS DOS PROFESSORES COM UM ALUNO SURDO NO CONTEXTO DA INCLUSÃO}

Este capítulo trata dos resultados obtidos a partir das reflexões das práticas pedagógicas dos professores da EMEF Coronel Raimundo Leão no contexto da inclusão de um aluno surdo. Buscou refletir como os professores utilizam suas práticas pedagógicas diante dos alunos com surdez.

A partir das reflexões das falas dos professores, observou-se que os docentes tem consciência da importância da inclusão dos alunos na escola, pois, eles são os principais responsáveis pelo processo inclusivo dos educandos, os mesmos vem se empenhando para buscar formação, buscando qualificação diuturnamente para saber lidar com essa realidade, porém as formações sobre inclusão, não acontecem frequentemente, o gestor incentiva os professores a buscarem formações sempre que possível, até mesmo em outros municípios. Entendem que o processo não é fácil, porém com o esforço de todos, vem conseguindo desenvolver metodologias que aos poucos vão se adequando as necessidades e peculiaridade dos discentes surdos.

Os professores tem consciência do papel da escola nesse processo, que ela é o elo de suma importância para a inclusão do surdo, porém tem enfrentado desafios na reorganização desse processo, procurando se organizar em todos os sentidos, objetivando atender as necessidades do educando. Essa reorganização estruturais tem se tornado um desafio para as escolas que precisam estar preparadas para garantir o processo inclusivo do aluno com surdez.

O gestor escolar, juntamente com sua equipe, tem abraçado a causa da inclusão, é um desafio que a escola tende a superar. Por isso, equipe técnica e professores precisam andar afinados em todos os sentidos, para poder garantir estrutura adequada ao discente surdo, os professores precisam ter o domínio na área da Libras para receber e atender as necessidades dos alunos .

A escola necessita se adequar diante das peculiaridades do aluno, estimulando, respeitando a Lei da inclusão, transformando um ambiente agradável e acolhedor aos educandos surdos, de forma que contemplem o aluno a receber o ensino de Libras, por entender que é a sua língua materna.

Percebeu-se que a EMEF Coronel Raimundo Leão, vem se esforçando arduamente para que o aluno surdo possa usufruir de uma educação inclusiva igualitária. Um dos caminhos encontrados para auxiliar na inclusão desse aluno, é buscar formação continuada na área da 
Libras, além de ser uma estratégia que os profissionais recorrem constantemente, auxilia os professores no desenvolvimento de suas metodologias que facilitem no seu fazer pedagógico, contribuindo para o processo de inclusão do discente. Contudo, ressalta-se que, as formações oferecidas aos professores não são recorrentes, dificultando no processo de inclusão do surdo. Santos vem dizer que,

Formação continuada ou formação contínua, ou formação em serviço, em sentido mais estrito, todas as formas deliberadas e organizadas de aperfeiçoamento profissional do docente, seja através de palestras, seminários, cursos, oficinas ou outras propostas. [...] voltadas para a qualificação do docente, tendo em vista a possibilidades de melhoria de sua prática pelo domínio de conhecimentos e de métodos de seu campo de trabalho (SANTOS, 1998, p.124).

Para a autora, o aperfeiçoamento profissional na área de atuação é fundamental para o crescimento cultural dos docentes, pois através das formações, o professor tem a possibilidade de adquirir novos conhecimentos e assim, contribuir na melhoria de sua prática pedagógica e no desenvolvimento de estratégias que propiciem no aprendizado e no processo inclusivo dos alunos surdos.

A formação continuada por ser de grande relevância, é indispensável na vida dos profissionais da educação, sobretudo, no aspecto da inclusão por ser um tema muito discutido pelos professores da EMEF Coronel Raimundo Leão. Contudo, evidenciou-se que, a falta de formação continuada na área da inclusão, sobretudo, no ensino de Libras, tem sido um dos empecilhos no desenvolvimento dos alunos, não só na escola pesquisada, mas no município como um todo, mais o gestor junto com os professores vem lutando para superar essa dificuldade. Segundo Libâneo,

O termo formação continuada vem acompanhado de outro, a formação inicial. A formação inicial refere - se ao ensino de conhecimentos teóricos e práticos destinados à formação profissional, completados por estágios. A formação continuada é o prolongamento da formação inicial, visando o aperfeiçoamento profissional teórico e prático no próprio contexto de trabalho e o desenvolvimento de uma cultura geral mais ampla, para além do exercício profissional. (2004, p.227).

Para o autor, o termo formação continuada vai desde o processo da formação inicial dos profissionais até chegar a um estágio mais avançado de conhecimentos teóricos e práticos, ou seja, a formação continuada busca o aperfeiçoamento dos profissionais para poderem desenvolver suas atividades práticas no seu campo de atuação de maneira mais prazerosa. 
A escola como um todo, tem buscado parcerias junto a Secretaria Municipal de Educação (SEMED) e Departamento de Educação Especial/Inclusiva do município de Cametá, no sentido de traçar metas de formação continuada inclusiva, com foco principalmente no ensino de Libras, aos profissionais da educação da EMEF Coronel Raimundo Leão, além de outras modalidades de ensino que contemplem no processo inclusão do aluno.

De acordo com as falas dos docentes, se houvesse formação específica e recorrente, teriam mais oportunidades para se qualificar na modalidade do ensino da Língua de Sinais e assim, desenvolver mais práticas pedagógicas inovadoras com os alunos surdos, utilizando-se de metodologias e dinâmicas prazerosas que iriam contribuir para o aprendizado e processo inclusivo dos discentes.

\section{CONSIDERAÇÕES FINAIS}

Concluímos, portanto, que o processo de inclusão de alunos surdos na EMEF Coronel Raimundo Leão, vem caminhando a passos lentos. Os gestores juntamente com sua equipe vem demonstrando esforços para proporcionar estrutura adequada aos discentes inclusos na escola, tem buscado inovar suas práticas pedagógicas para garantir a aprendizagem dos alunos surdos no ensino da Libras. As barreiras, sobretudo no ensino dessa língua são evidentes, pois os docentes ficam muito presos apenas, em algumas metodologias, por não terem o domínio da língua de sinais, causando dificuldades para inovar suas práticas pedagógicas.

Tem sido um desafio lidar com o processo de inclusão na EMEF Coronel Raimundo Leão. Segundo o gestor, a escola necessita de recursos para reestruturar o ambiente escolar, transformando num ambiente acolhedor adequado para atender as necessidades dos surdos e de outros alunos que possuem outras deficiências.

$\mathrm{Na}$ fala do gestor, se a escola tivesse recursos suficientes, ajudaria muito nas transformações e adaptações da escola e na contratação de profissionais capacitados para ministrar cursos de formação continuada na área da inclusão, com foco no ensino da Libras aos professores que precisam de capacitações para inovar suas práticas de ensino e mediar os surdos na sua língua materna, pois os recursos do FNDE, tem sido muito limitado.

Observou-se que apesar dos esforços da gestão em garantir a inclusão dos alunos surdos, os professores buscam qualificação na área da inclusão, porém a (SEMED), órgão responsável em proporcionar formações, tem dificuldade para ofertar cursos aos professores da EMEF Coronel Raimundo Leão e também das escolas da cidade, devido a demanda do município ser muito grande, e também por ter uma equipe do departamento de educação inclusiva muito reduzida, dificultando assim, o processo. Além da oferta dos cursos na cidade, 
precisam atender a zona rural e ribeirinha, isso, quando tem recursos para fazer a formação, tornando restrita a oferta de cursos de formação continuada, ficando limitado a qualificação dos docentes.

Como sugestão, acreditamos ser possível a escola, enquanto ambiente de transformação, firmar parceria com a Universidade Federal do Pará, Campus Cametá, (UFPA), através do Grupo de Estudos Surdos da Amazônia Tocantina (GESAT), Centro de Inclusão Educacional de Cametá (CIEC), Centro de Formação de Professores (CEFOP), e discutir propostas para construção de projetos de formação continuada para os professores que tanto necessitam desse aprimoramento profissional na área da inclusão/Libras e assim, superar as dificuldades e inovar suas práticas pedagógicas, no sentido de superar esse problema detectado.

Por saber que a inclusão está garantido em Lei, precisa ser aderido com propriedade nas escolas, sabe-se que o processo inclusivo não é fácil, pois requer muito empenho de toda a equipe escolar. Segundo Mantoan (2003, p.16), pioneira nos estudos inclusivos, "inclusão implica uma mudança de perspectiva educacional, pois não atinge apenas alunos com deficiência e os que apresentam dificuldade de aprender, mais todos os demais, para que obtenham sucesso na corrente e educacional educativa geral". Por isso, tanto a escola, quanto os departamentos educacionais responsáveis pelo processo, devem abraçar essa causa e fazer o processo inclusivo acontecer, não somente na EMEF Coronel Raimundo, mas em todas as escolas do município de Cametá.

Apesar da inclusão que vem sendo discutida intensamente nas últimas décadas, ainda há muitas lacunas que precisam ser compreendidas pela comunidade escolar e sociedade, para que de fato, todos tenham a plena consciência do processo de inclusão dos alunos que tanto merecem ser amparados e reconhecidos por todos, não deve ser visto como barreiras e sim como oportunidades de garantia de direitos e acesso aos ambientes escolares e públicos, é preciso valorizar as diferenças de cada um.

\section{REFERÊNCIAS}

BENTO, Nanci A. Os Cinco Parâmetros Fonológicos. Folder Explicativo na Apresentação da Disciplina Let 594- Psicolinguística Aplicada ao Português 1. Salvador: Universidade Federal da Bahia, 2008. Não Publicado.

BRASIL. Ministério da Educação. Secretaria de Educação Especial. Política Nacional de Educação Especial. Brasília, Secretaria de Educação Especial, 1994. 
Ministério da Educação. Secretaria de Educação Especial. Decreto No 5.626, de 22 de dezembro de 2005. Regulamenta a Lei No 10.436, de 24 de abril de 2002.

. Lei Federal 10.436 de 24 de Abril de 2002. Dispõe sobre a Língua Brasileira de Sinais - Libras e dá outras providências.

. Ministério da Educação. Secretaria de Educação Especial. Diretrizes Nacionais para a Educação Especial na Educação Básica. Brasília: MEC/SEESP, 2001.

Ministério da Educação e Cultura. Portaria CENESP/MEC, n. 69. Brasília, 1986.

. Constituição da República Federativa do Brasil. 1988.

. Ministério da Educação. Secretaria de Educação Especial. Política Nacional de Educação Especial. Brasília: MEC/SEESP, 1994.

. Ministério da Educação. Lei de Diretrizes e Bases da Educação Nacional. LDB 9.394, de 20 de dezembro de 1996.

BRITO, L. F. et. al. Língua Brasileira de Sinais-Libras. In:. (Org.) BRASIL, Secretaria de Educação especial. Brasília: SEESP, 1998.

DECRETO no 5.626/05 - Regulamenta a Lei 10.436 que dispõe sobre a Língua Brasileira de Sinais - LIBRAS.

FERNANDES, Sueli Educação de surdos/Sueli Fernandes - 2 ed. Atual.- Curitiba Ibpex, 2011.

GESSER, A. LIBRAS?: que língua é essa? crenças e preconceitos em torno da língua de sinais e da realidade surda. São Paulo: Parábola Editorial, 2009.

LDB: Lei de diretrizes e bases da educação nacional. - 2. ed. - Brasília : Senado Federal, Coordenação de Edições Técnicas, 2018.

LIBÂNEO, J. C. Organização e Gestão da Escola -Teoria e Prática. Goiânia: Editora Alternativa, 2004.

MANTOAN, M.T. E. Inclusão escolar: O que é? Por quê? Como fazer? São Paulo: Editora: Moderna, 2003.

SANTOS, L. L. C. P. Dimensões Pedagógicas E Políticas Da Formação Contínua. In: VEIGA, I. P. A. (Org.). Caminhos da Profissionalização do Magistério. Campinas: Papirus, 1998. 